\title{
Spontaneous closure of pediatric traumatic macular hole: case report and spectral-domain OCT follow-up
}

\author{
Fechamento espontâneo de buraco macular traumático em criança: relato de caso e seguimento por OCT
}

Juliana de Filippl Sartori ${ }^{1}$, Francisco Stefanini², Nilva Simeren Bueno de Moraes²

\section{ABSTRACT}

Spontaneous closure of a traumatic macular hole (TMH) is an unusual outcome. Optical coherence tomography (OCT) and clinical follow-up enabled monitoring of this resolution during a period of a few weeks. We describe a case of spontaneous closure of a TMH with complete visual recovery in a 15 year-old boy and show the follow-up of the macular hole obtained using the Spectral Domain OCT.

Keywords: Eye injuries/etiology; Eye injuries/therapy; Visual acuity; Tomography, optical coherence; Retinal perforations; Case report

\section{RESUMO}

Ofechamentoespontâneo de umburaco macular traumaticoéevento raro. A tomografia de coerência óptica (OCT-Spectral domain) éo exame de eleição para o seu acompanhamento. Descrevemos um caso defechamento espontâneo de buraco macular traumático em menino de 15 anos deidade, com recuperação visual completa em apenas 8 semanas, documentado por tomografia de coerência óptica.

Descritores: Traumatismos oculares/etiologia; Traumatismos oculares/terapia; Tomografia de coerência óptica; Perforações retinianas; Relato de caso

\section{INTRODUCTION}

Traumatic macular hole (TMH) is a well-known complication of blunt trauma, but its exact mechanism remains unclear. Spontaneous closure of a TMH is reported to occur in 10-66\% of cases in adults $^{(1,2)}$. The adhesion of posterior hyaloid to the ILM is strong in children and young adolescents ${ }^{(3)}$. Therefore, it can be difficult to achieve a complete posterior vitreous detachment (PVD) mechanically in pediatric eyes. This creates a particular challenge for successful surgery in pediatric patients. There is no study comparing the surgical approach versus expectant management in pediatric traumatic macular hole. We describe a case of spontaneous closure of a TMH with complete visual recovery in a 15-year-old boy and show the optical coherence tomography (OCT) follow-up obtained using the Spectral Domain OCT (Spectralis OCT; Heidelberg Engineering, Heidelberg, Germany).

\section{CASE REPORT}

A 15-year-old boy was accidentally hit in the left eye by a soccer ball. He first noted blurred vision 10 days after the injury. His best-corrected visual acuity of the affected eye was 20/100. The intraocular pressure was $15 \mathrm{mmHg}$. The anterior biomicroscopy was normal. Fundus examination revealed an oval, full-thickness macular hole, but no retinal detachment was observed. The Watkze-Allen test was positive.

Conservative management was initiated, and the patient was followed-up with clinical examinations and Spectralis OCT imaging.
The baseline OCT of the left eye, performed at the first visit (Figure 1), shows a full thickness macular hole and it is observed intraretinal cysts.

Four weeks after the first exam, his best-corrected visual acuity improved from 20/100 to 20/60. There was a significant improvement in the fundoscopic appearance that was confirmed by OCT (Figure 2), showing partial resolution of the macular hole, remaining, however, the discontinuity of the line that represents the junction of inner and outer segments of photoreceptors (IS / OS). It is also observed an area of hyporeflectivity beneath the external limiting membrane (ELM).

Eight weeks after the first exam, the best-corrected visual acuity improved from 20/100 to 20/25. Complete resolution of the macular hole was observed, as determined by both fundoscopy and OCT imaging. At this time, the OCT (Figure 3 ) showed a complete resolution of the full-thickness macular hole, there was no area of hyporeflectivity beneath the ELM, but the IS/OS line remained discontinuous. Thickening and wrinkling of the internal limiting membrane (ILM) werealso observed.

\section{DISCUSSION}

Eyeball trauma is one of the main causes of $\mathrm{TMH}$, and was first reported by Knapp in 1869. Two different mechanisms are believed to lead to the formation of TMH, depending on whether the posterior hyaloid is attached or detached. ATMH is thought to occur either as a primary concussive tear or as a secondary breakdown of traumatically induced cystoid changes ${ }^{(2)}$. In the case in question, the OCT showed a
Funding: No specific financial support was available for this study.

Disclosure of potential conflicts of interest: J.F.Satori, None; F.Stefanini, None; N.S.B.Moraes, None.

Correspondence address: Juliana de Filippi Sartori. Av. Indianópolis, 2626 - São Paulo - SP 04520-013 - Brazil - E-mail: Juliana@vizarth.com 
TMH with an intact posterior vitreous face already 10 days after the injury. These findings suggest that the TMH was produced as a concussive tear. In other reports, several explanations have been proposed for the spontaneous resolution of TMH: cell proliferation at the base of the hole; formation of a contractile epiretinal membrane resulting in shrinkage and closure of the hole, and complete detachment of the posterior hyaloid from the foveal area resulting in the release of an anteroposterior traction ${ }^{(4)}$. The first explanation is of significance regarding the case under review. The small opening of the TMH could have favored the proliferation of glial cells to bridge the gap. The development of an epiretinal membrane was not observed. The third explanation was not applicable to the patient because there was no evidence of vitreoretinal traction, and the vitreous body remained attached throughout the follow-up period. Common features between this patient and the patients with spontaneous closure of $\mathrm{TMH}$ described in the literature were the young age, the small size of the macular hole, and the failure of a posterior hyaloid detachment ${ }^{(1)}$.

The relatively higher rate of spontaneous closure of TMH (10-66\% in adults) $)^{(1,2)}$ may be explained by an adherent posterior vitreous membrane $^{(5)}$ and the absence of permanent traction from an epiretinal membrane compared to idiopathic macular holes ${ }^{(6)}$.

The time elapsed from the trauma to the spontaneous closure is variable. The case published by Yeshurun et al. lasted 5 months ${ }^{(7)}$, the three reported by Kusaka et al. lasted between 3 and 4 months ${ }^{(8)}$, and
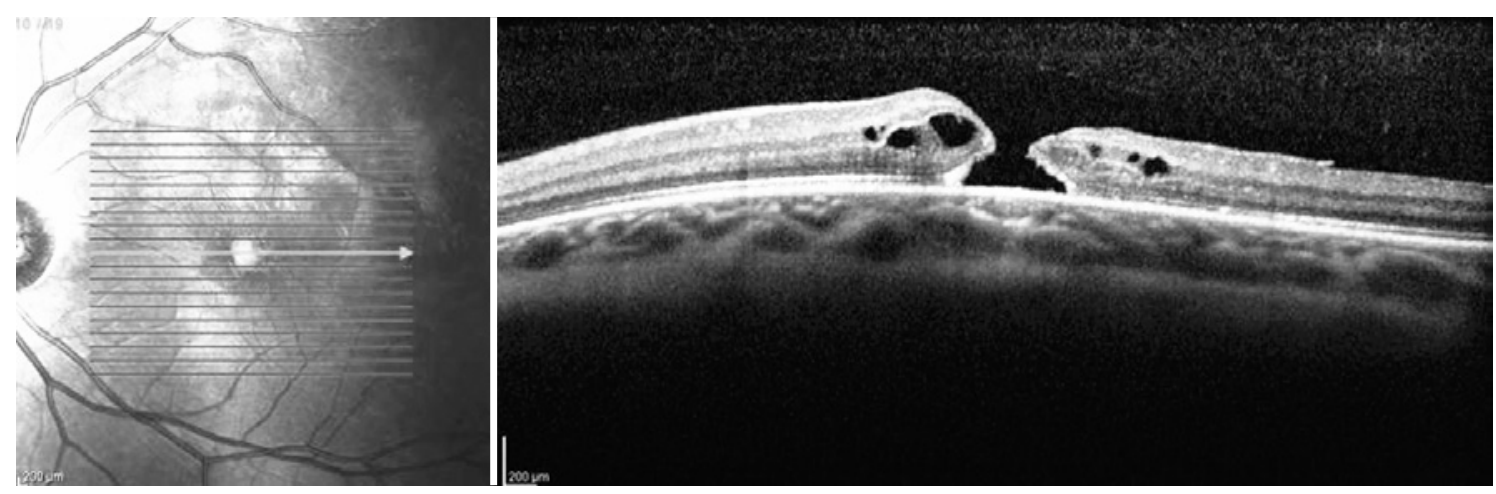

Figure 1. Optical coherence tomography performed at the first visit showing a full-thickness macular hole with intraretinal cysts, VA: 20/100.
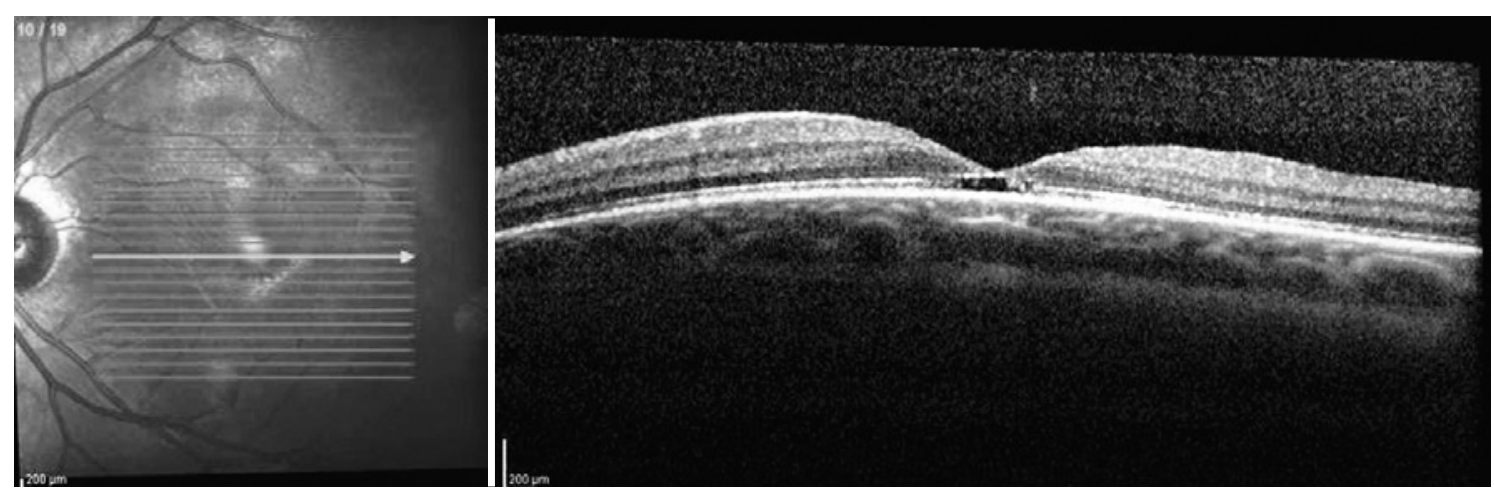

Figure 2. Optical coherence tomography performed 4 weeks after the first visit showing an improvement in the OCT exam with partial resolution of macular hole, discontinuity of the IS/OS line and external hyporeflectivity; and in the VA: 20/60.
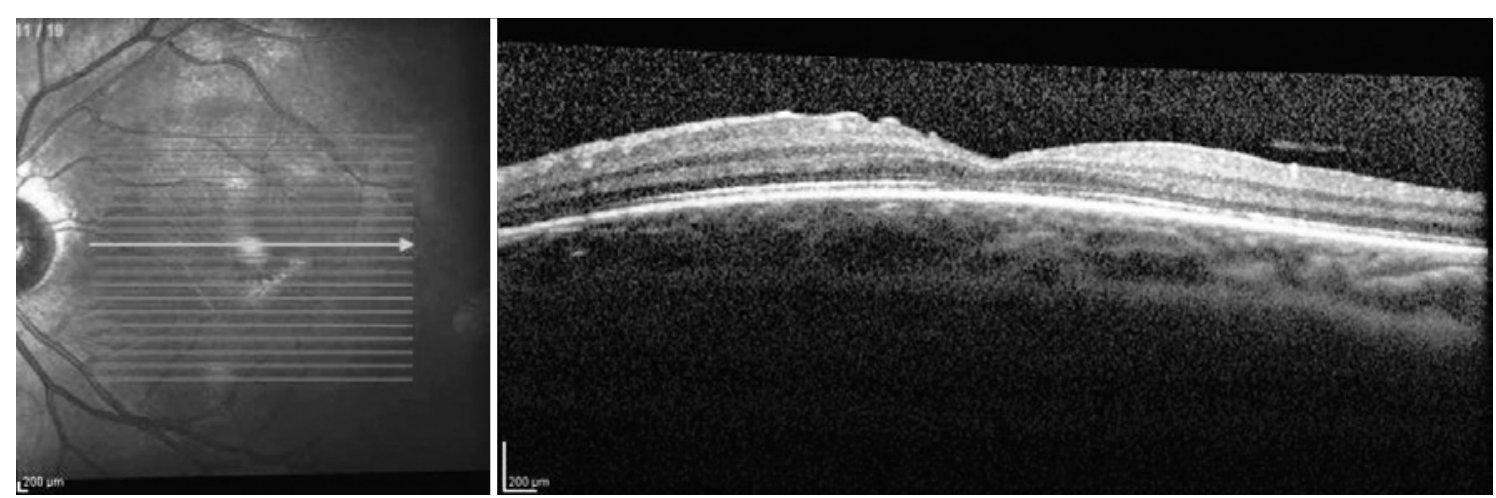

Figure 3. Eight weeks after the trauma, complete resolution of the macular hole was observed by both fundoscopy and OCT that also presents thickening and wrinkling of the internal limiting membrane (ILM) and shows that IS/OS line remains discontinuous. At this time: VA: $20 / 25$. 
those reported by Yamada et al. lasted between 4 and 6 months ${ }^{(9)}$. In 2002, Yamashita et al. presented eight cases that took between 1 week and 4 months to close, citing Mizusawa (9 months), Tomii (14 days to 5 months), Murakami (3 months) and Parmar (2 months)(2). In 2006, Lai et al. published a case of TMH with secondary retinal detachment that took three weeks to self-seal ${ }^{(10)}$.

Spectral-domain (SD) (or Fourier-domain) OCT constitutes an improved technique for retinal imaging. It uses a spectrometer in the detection arm of the interferometer to convert depth information. This enables detection of weaker signals and increases imaging speed by 25 to 50 times over standard OCT, performing up to 19,000 A-scans per second ${ }^{(11)}$.

We found that OCT imaging is useful in visualizing anatomical $\mathrm{TMH}$ closure. In our case, anatomical TMH closure correlated with visual recovery.

It is remarkable to observe that, at 8 weeks in the follow-up, despite VA improvement, the SD-OCT showed anatomic abnormalities, as thickening and wrinkling of the ILM, and discontinuity of the IS/ OS line.

Further studies will be necessary to determine the exact association between macular hole closure and ultimate visual recovery.

\section{CONCLUSION}

In conclusion, OCT is a valuable tool for the better understanding of the development and the spontaneous resolution of TMH. In the case under consideration, the closure of the TMH was not facilitated by the release of the posterior hyaloid traction on the edge of the hole, but by the proliferation of bridging tissue facilitated by the small opening of the hole. Recognition of the possibility of spontaneous closure of small macular holes is important and has clinical value. For young patients with a traumatic macular hole, it is, therefore, probably better to wait at least six months from their ocular concussion to allow for the possibility of any spontaneous hole closure.

Significant visual recovery is possible even in the presence of associated chorioretinal atrophy. Serial OCT imaging of the macular hole is useful in gauging ultimate visual recovery.

More data will be necessary to determine whether the surgical or expectant approach is the most appropriate for traumatic macular holes in children.

\section{REFERENCES}

1. Mitamura Y, Saito W, Ishida M, Yamamoto S, Takeuchi S. Spontaneous closure of traumatic macular hole. Retina. 2001:21(4):385-9.

2. Yamashita T, Uemara A, Uchino E, Doi N, Ohba N. Spontaneous closure of traumatic macular hole. Am J Ophthalmol. 2002;133(2):230-5.

3. Sebag J. Age-related differences in the human vitreoretinal interface. Arch Ophthalmol. 1991;109(7):966-71.

4. Takahashi H, Kishi S. Optical coherence tomography images of a spontaneous macular hole closure. Am J Ophthalmol. 1999;128(4):519-20.

5. Yanagiya N, Akiba J, Takahashi M, Shimizu A, Kakehashi A, Kado M, et al. Clinical characteristics of traumatic macular holes. Jpn J Ophthalmol. 1996;40(4):544-7

6. Bresgen M, Heimann K. [ldiopathic macular foramen: new aspects of staging and possible therapeutic concepts]. Klin Monatsbl Augenheilkd. 1995;206(1):2-12. German.

7. Yeshurun I, Guerrero-Naranjo JL, Quiroz-Mercado H. Spontaneous closure of a large traumatic macular hole in a young patient. Am J Ophthalmol. 2002;134(4):602-3.

8. Kusaka S, Fujikado T, Ikeda T, Tano Y. Spontaneous disappearance of traumatic macular holes in young patients. Am J Ophthalmol. 1997;123(6):837-9.

9. Yamada H. Sakai A Yamada E, Nishimura T, Matsumura M. Spontaneous closure of traumatic macular hole. Am J Ophthalmol. 2002;134(3):340-7.

10. Lai MM, Joshi MM, Trese MT. Spontaneous resolution of traumatic macular hole-related retinal detachment. Am J Ophthalmol. 2006;141(6):1148-51.

11. Wojtkowski M, Bajraszewski T, Gorczyńska I, Targowski P, Kowalczyk A, Wasilewski W, Radzewicz C. Ophthalmic imaging by spectral optical coherence tomography. Am J Ophthalmol. 2004;138(3):412-9.

\title{
xincongresso da \\ XVII Congresso da \\ Sociedade Brasileira de Uveítes
}

\section{4 a 16 de março de 2013}

\author{
Informações:
}

E-mail: wiltonfeitosa@hotmail.com

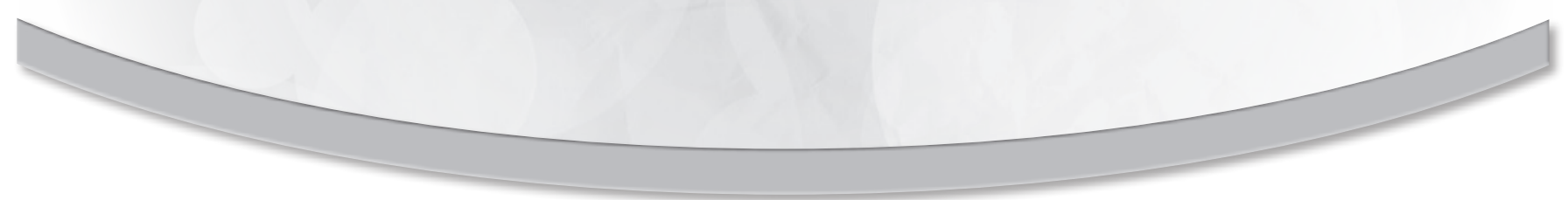

